\title{
Self-Desiccation of Cemented Paste Backfill and Implications for Mine Design
}

\author{
M. Grabinsky Lassonde Institute for Engineering Geoscience, University of Toronto, Canada \\ P. Simms Carleton University, Ottawa, Canada
}

\section{INTRODUCTION}

The hydraulic and mechanical properties of Cemented Paste Backfill (CPB) that are of principle interest in Geomechanical Mine Design include rheology, suction (the Soil Water Characteristic Curve or Water Retention Curve), permeability, stiffness, and static and dynamic strength (including resistance to liquefaction). All of these properties change as the binder in the CPB hydrates. In some, and perhaps most, mining applications the rate of hydration, and therefore the rate of hydraulic and mechanical property change, occurs on a time scale comparable to the rate of CPB delivery to and filling of the stope. This means that the CPB's properties are evolving even as it is being deposited and overprinted. This fact can have serious implications for how we interpret total stress cell results, how arching develops both within the stope and across the fill barricades, how fill barricades are designed and constructed, and how we evaluate the CPB's ability to carry its own self-weight during filling (i.e., resistance to static liquefaction during filling) and subsequent mining (i.e., resistance to dynamic liquefaction during blasting in proximity to recent fills).

This paper begins by considering some initially unexpected results from an in situ investigation that illustrates the interaction between rate of binder hydration and rate of stope filling. The framework for conducting tests to evaluate CPB's evolving hydraulic and mechanical properties is then considered. Some initial test results involving static monotonic and cyclic loading of CPB are then reviewed, and the mine design implications of these test results are considered. The conclusions arising from this work are not yet meant to be used for practical design, but rather point to the extensive research and development that is still required before we can rationally carry out optimized design of CPB fills and their barricades.

\section{CASE STUDY}

The case study involves the Golden Giant Mine, one of three mines in the Hemlo mining camp in Marathon, Ontario, Canada. Many aspects of this study have already been reported (e.g., Grabinsky et al., 2005; le Roux et al., 2005; le Roux et al., 2004; le Roux et al., 2002); the focus in this paper will be on the interaction between the rate of hydration and the rate of stope filling.

The test stope was sampled using triple core diamond drilling from below and block sampling from above, and the core was subjected to bulk property evaluation (amongst other tests). The bulk properties of primary interest were void ratio, degree of saturation, and water content. The investigators originally expected a 
gradient in the fill properties, specifically decreasing void ratio with depth due to self-weight consolidation, and an increasing degree of saturation with depth due to drainage. However, the bulk properties were remarkably consistent with depth showing only "random variation" about their mean values. The bulk properties were then compared with each other using the phase relationship

$$
e S r=w G S
$$

where $e$ is the void ratio, $w$ is moisture content (mass of water over mass of solids, which is the term used throughout this paper), $G s$ is specific gravity and $S r$ is degree of saturation. The results of this comparison are shown in Figure 1.

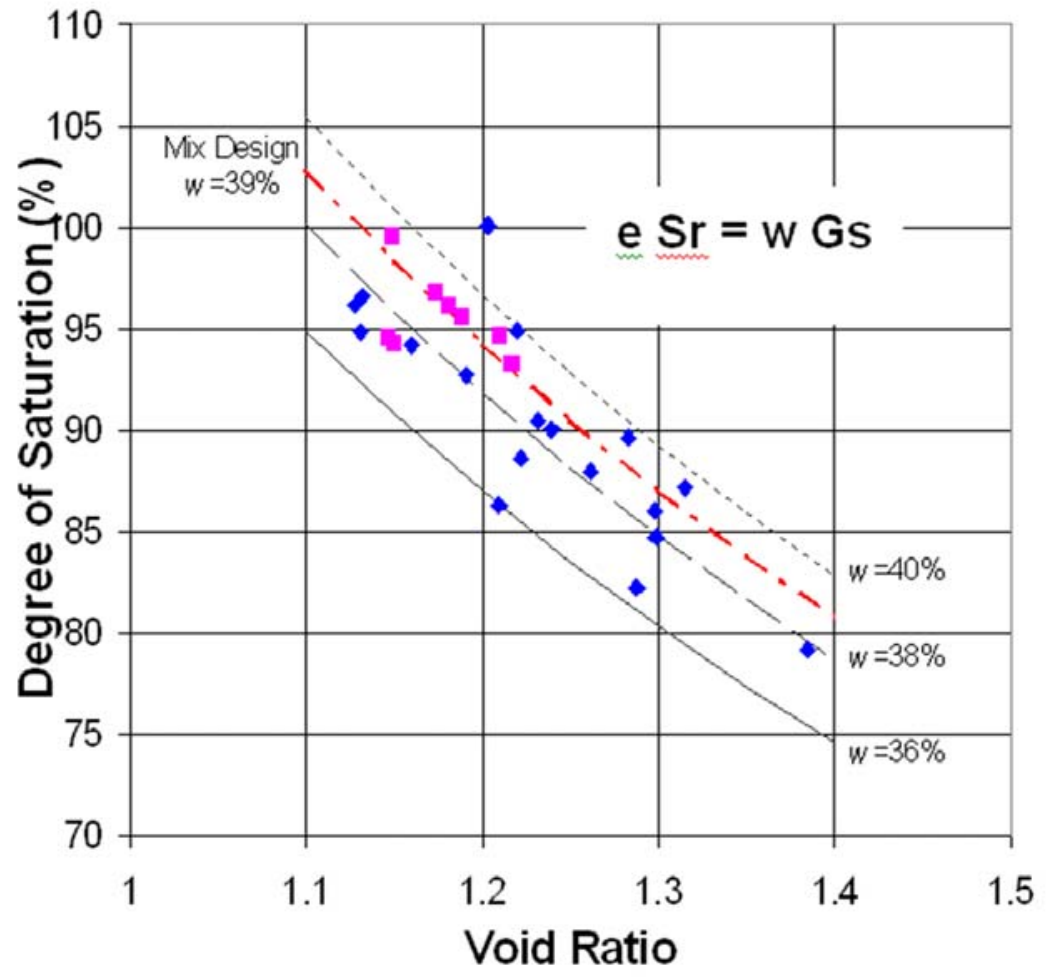

Figure 1 Relationship between void ratio, moisture content, and degree of saturation for undisturbed samples retrieved from a CPB test stope

The results presented in Figure 1 are interpreted as follows. The design moisture content of 39\% appears to be retained (the variation in moisture content exhibited in Figure 1 can be explained by incomplete mixing in the paste plant, and the fact that the disk filters used to produce filter cake are not all equally efficient resulting in slightly dryer or wetter than average filter cake from any particular disk). The void ratio, however, increases and the corresponding degree of saturation decreases for the various samples, leading one to ask: Where is the increase in air coming from? The retrieved samples do indeed show evidence of air entrainment even at scales observable with the naked eye, as shown in Figure 2. 


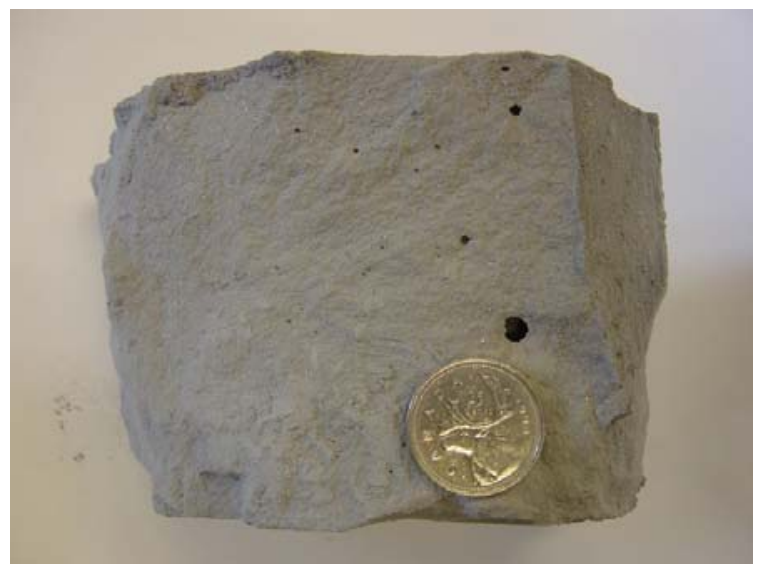

\section{Figure 2 An undisturbed CPB sample showing evidence of entrained air (a Canadian $25 \phi$ coin is shown for scale)}

Indeed, similar entrained air voids could be observed at smaller scales under optical microscopes and even using micro-CT (computed tomography) scanners. It is believed that this air entrainment results from incomplete breakdown of the filter cake during mixing and transport, and also as a result of end-of-pipe deposition from the top of the stope which results in paste "raining" down on the fill below.

Even if the air were entrained in the CPB during mixing, transport and placement, it may be surprising that self-weight consolidation did not play a bigger role than apparently was the case (i.e., the void ratio did not decrease with depth in a statistically significant way). To investigate this observed phenomenon a series of consolidation tests were carried out in cells approximately $15 \mathrm{~cm}$ diameter by $15 \mathrm{~cm}$ high. The vertical total load on the samples was varied to simulate the overburden resulting from different fill rates and the sample's consolidation behaviour was monitored. The results for these tests are shown in Figure 3, and show that for the extreme condition of highest binder / lowest fill rate considered in the test suite, which is representative of the conditions under which the in situ samples were deposited, the rate of hydration is sufficient to effectively suppress consolidation of the sample due to accumulating overburden. Note that the test method used does not simulate the effects of arching within the stope; if arching does indeed exist, then the change in void ratio would be even less than that predicted by the test method used and the results shown in Figure 3 .

Finally, the influence of an unsaturated state on the rate of drainage should be considered as a contributing factor towards the degrees of saturation observed in the samples retrieved from in situ. Generating the Soil Water Characteristic Curve (SWCC, also known as Water Retention Curve) for a hydrating material is a difficult task (e.g., Godbout et al., 2004) and one for which no standard test method currently exits. The following simulation was therefore carried out to determine an upper bound for the amount of drainage that could plausibly occur. The SWCC for the uncemented paste was used in the analysis as this would result in the most free draining material (the effect of binder hydration is to increase the suction characteristics of the $\mathrm{CPB}$ ), and free draining boundary conditions were simulated around the fill in order to maximize the capacity of the surrounding environment to receive any water draining from the fill. It was assumed that the 
paste was initially placed in a saturated state $(S r=1)$ and a draining time of six months was simulated, corresponding to the actual time after deposition at which the samples were taken from the stope. The analysis results show that the bulk of the stope remains at $85 \%$ saturation $(\mathrm{Sr}=0.85)$ even under these most plausibly free-draining conditions. Hence, if the influence of binder hydration on the SWCC is taken into account, and if the actual permeability of the generally massive rock at the mine is considered as opposed to the idealized free-draining boundaries used in the simulation, then it is unlikely the degrees of saturation observed in the in situ samples can be explained by drainage, and hence air entrainment seems most likely.

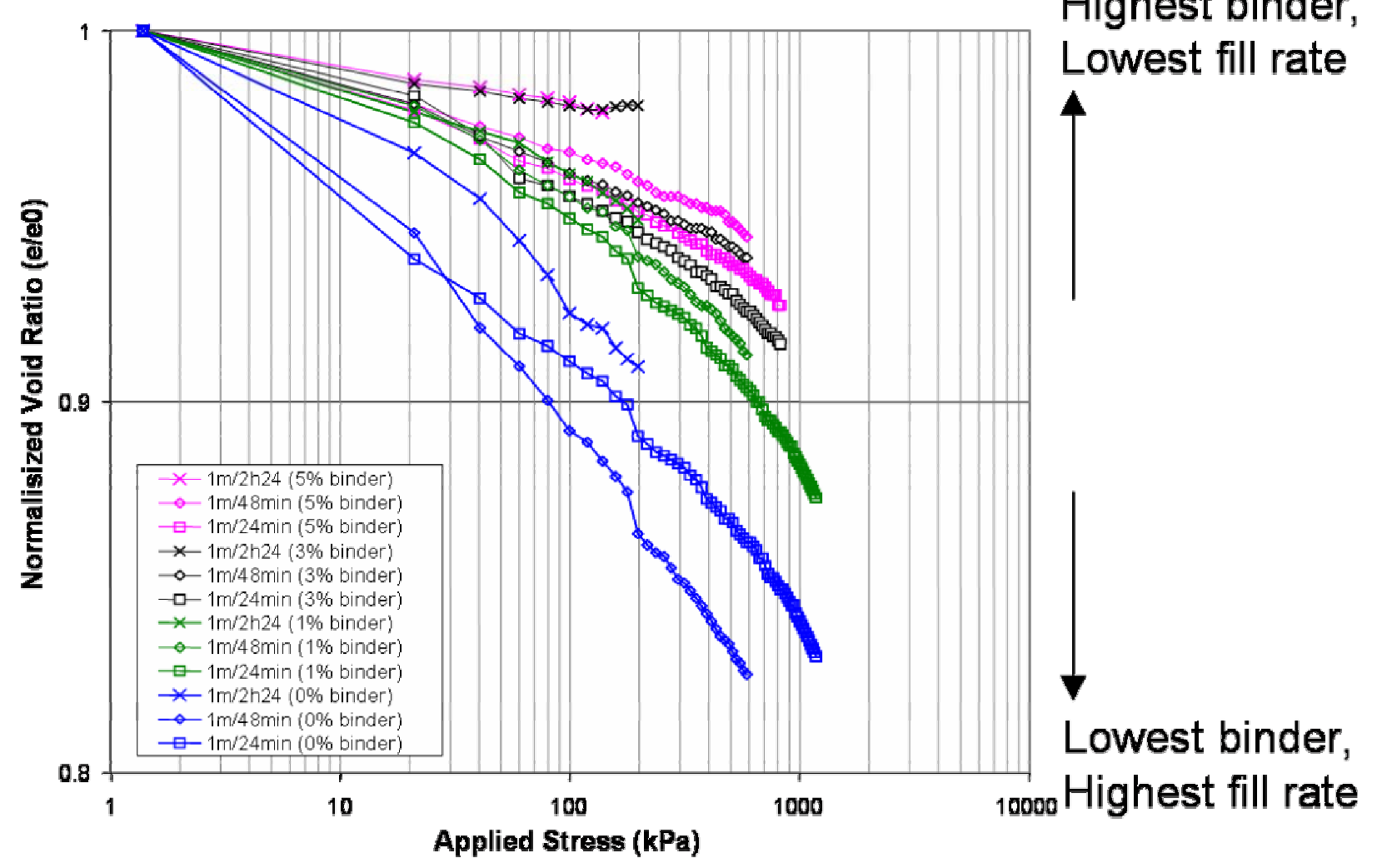

Figure 3 Consolidation behaviour of a CPB sample subjected to different rates of loading (corresponding to different fill rates in a stope)

The case study therefore illustrates the important effect that binder hydration can have on the realized in situ properties of $\mathrm{CPB}$. The preceding observations lead to further important design implications: Does the hydration-enhanced stiffness of the paste increase the generally beneficial effects of arching, both within the fill itself and particularly around the fill barricade? What are the total stresses, pore water pressure, and effective stress distributions set up within the fill? Could suctions exist within the water phase over a significant portion of the fill? How do the competing effects of high void ratio and high degree of saturation versus increased stiffness and strength and states of suction combine to affect liquefaction potential? Steps towards addressing these issues are considered in the following section. 


\section{A FRAMEWORK FOR ASSESSING CPB'S PROPERTIES}

The hydraulic and mechanical properties of uncemented paste can generally be adequately described for mine design purposes within the frameworks of soil mechanics $(S r=0$ or 1) and unsaturated soil mechanics $(0<S r<1)$. However, binder hydration adds a transient effect that considerably complicates the quantitative description of paste's properties. Workers in conventional concrete materials technology have observed a process they describe as self-desiccation (Acker, 2004; Kim and Lee, 1999) acting in cement pastes. In general, a variety of processes can occur during hydration which consume water or bind water to the hydration products, and the net volume of the hydration products themselves are calculated to be less than that of the constituent materials. Therefore, the process of hydration has the combined effect of reducing the total volume of the water phase, increasing the water retention characteristics of the solid phase, and increasing the strength and stiffness of the solid phase. This effect in CPB is demonstrated in the following sub-sections.

\subsection{Self-desiccation of CPB}

The suctions of interest in this paper are generally less than about $200 \mathrm{kPa}$, for which tensiometers may be used to measure the suctions directly. The device used in this study is a T5 tensiometer from Delta-T Devices (Cambridge, UK) which is capable of measuring pore water pressures up to about $200 \mathrm{kPa}$ and suctions up to about $200 \mathrm{kPa}$. The air entry value (AEV) of the tensiometer tip is rated in excess of $300 \mathrm{kPa}$, however, in practice the device typically desaturates within the inner column of water leading to the electrical resistance strain gauge. Achieving high suction values requires proper conditioning of the tensiometer, which is carried out through a process of initial filling with de-aired water and then cycling between a vacuum chamber and an overpressure chamber. This relatively straightforward process results in reliable readings up to $200 \mathrm{kPa}$ or more, and the desaturation of the device is marked by a sudden and almost complete loss of suction so that one knows precisely when the data is no longer reliable.

Sample test results are shown in Figure 4. The T5 is inserted into a CPB sample mix and plastic wrap is used to seal the test cylinder and prevent loss of water due to evaporation. Suctions may be observed immediately if the mix is initially quite dry; however, if the mix is wet enough such that some initial self-weight consolidation occurs, then the top free water must be removed to prevent a positive pressure head and to initiate the development of suction. The samples shown in Figure 4 exhibit consistent suction development with time, peaking at over $100 \mathrm{kPa}$ in about 6 days. Note that suction is a spherical or bulk component of stress, similar to pore water pressure. Therefore, $100 \mathrm{kPa}$ of suction is potentially similar to a triaxial sample initially subjected to $100 \mathrm{kPa}$ of all-round confining pressure before the deviator load is applied. Many triaxial test results reported in the literature use a range of confining pressure of $0-150 \mathrm{kPa}$, therefore the effect of $100 \mathrm{kPa}$ suction must be considered as potentially significant to the strength that might be realized in situ. 


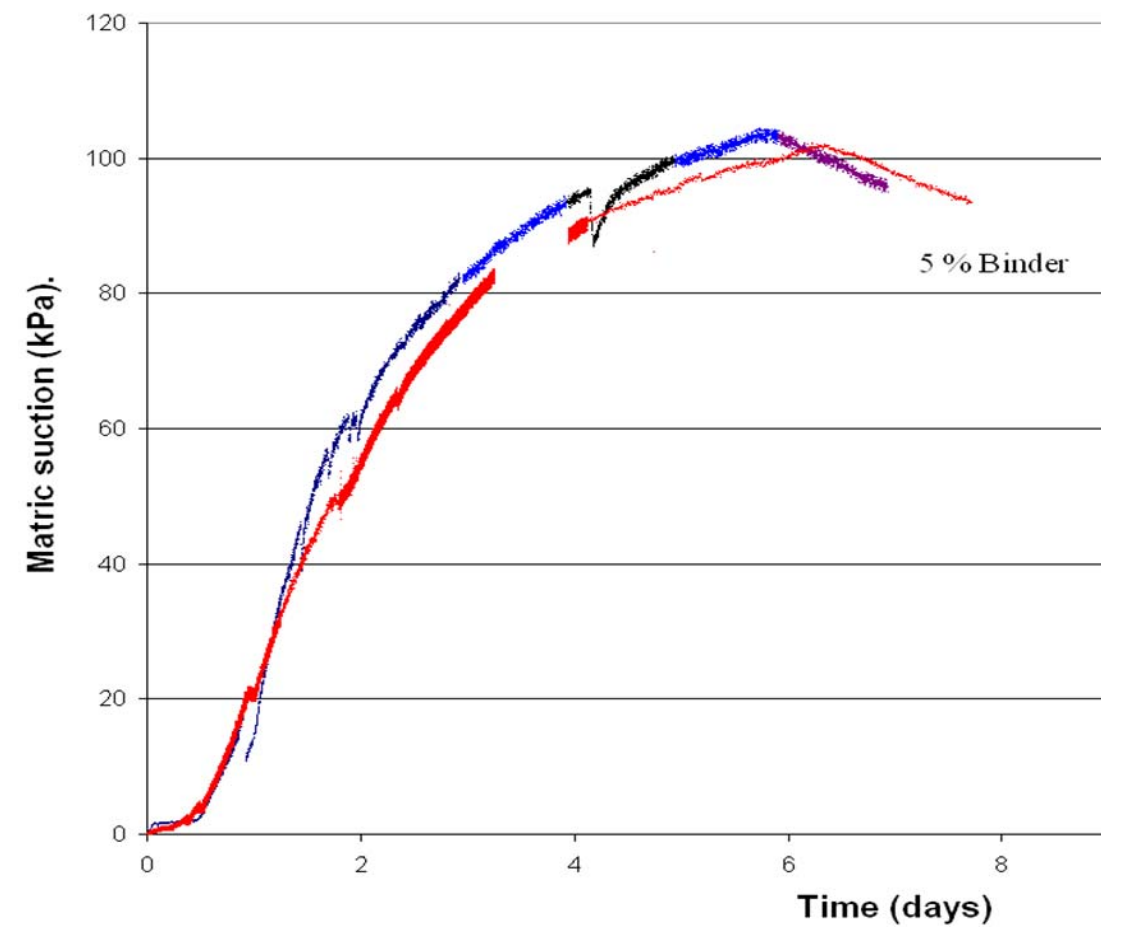

\section{Figure 4 Development of suctions (i.e. self-desiccation) in two CPB samples}

The suctions, however, may also be diminished through the application of an externally applied confining stress, which will tend to reduce the skeletal volume and therefore void ratio of the sample, thereby relaxing the tensile stresses that bound the water to the particle surfaces. This is investigated in next sub-section.

\subsection{Suction development during 1-D compression}

A 1-D compression (oedometer) stress cell was retrofitted with a T5 and placed in a pneumatic load frame controlled by an electro-pneumatic pressure regulator. The system was calibrated so that the vertical load applied to the sample corresponds to a prescribed rate of rise used in stope filling, assuming arching does not occur (i.e., total overburden stress conditions). Initial suctions were allowed to develop in the sample, such as might occur in a "paste plug" allowed to cure in front of a fill barricade (Figure 5). The subsequent staged filling phase is simulated by increasing the applied load, and the suppression and redevelopment of suctions are monitored between each filling stage using the T5. With reference to Figure 5, it can be seen that the immediate application of load results in an immediate reduction in suction, however, this suction is almost completely regained during the first few stages of loading. As the total applied load increases, the suctions are eventually overcome until, at the end of filling, the suctions have almost disappeared. It is significant, however, that suctions exist at all. In contrast, if one used a conventional saturated soil mechanics model then a significant head of pore water pressure would be predicted. Note that at the end of the test in Figure 5, upon removal of the applied load there is an elastic rebound of the paste skeleton and a significant suction reappears. 


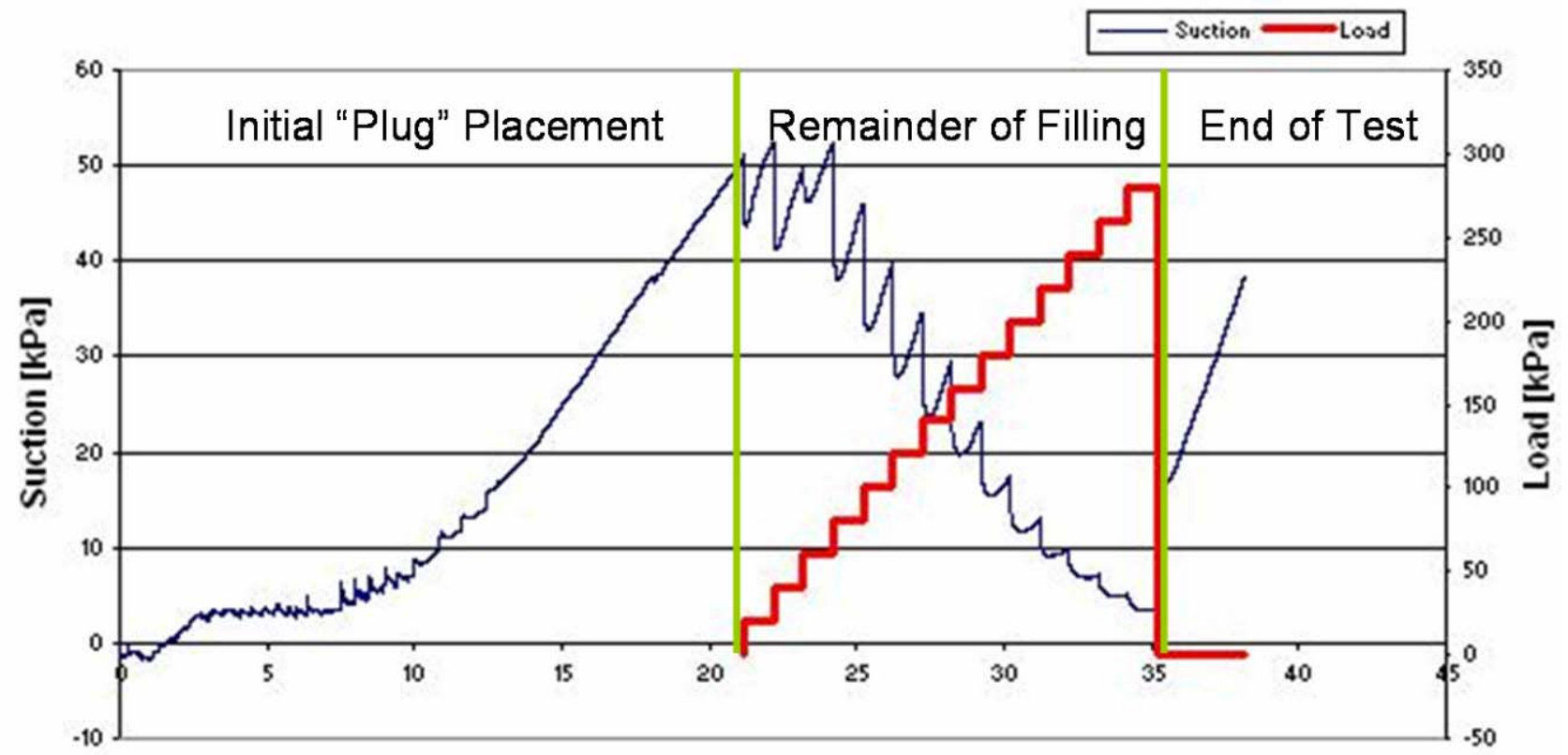

Time [hrs]

Figure $5 \quad$ Suction suppression during 1-D compression

\subsection{Suction development during triaxial compression}

The tests described in this sub-section are actually uniaxial tests where the base platen has been retrofitted with a T5 in order to monitor the suction within the sample. Although no externally applied pressure exists on the sample, a form of confinement does exist through the development of suction. This assumption is probably valid so long as discrete planes do not form that would break the continuity of the suction across the plane's surface. The test results are therefore in essence "triaxial". It must be recognized that the triaxial test, as it is carried out here, is actually a combination of spherical (or pressure, or bulk) stress loading and additional axial loading from the loading ram. Monitoring the suction response is therefore akin to monitoring the pore pressure response in a convention undrained (CU) triaxial test, and the changes in suction (or pressure) can be related to the potential for volume change in the same way as for the conventional test.

The results shown in Figure 6 are for a sample where curing was allowed to progress until the suction reached a magnitude of approximately $80 \mathrm{kPa}$, at which point additional axial loading commenced. The slopes of the unload-reload loops may be taken as indicative of the elastic modulus, and the intercepts of these loops with the strain axis signifies the magnitude of accumulated plastic axial strain. The moduli and plastic strain interpreted in this way are given in Table 1. Note that just after the peak stress is reached there are two coincident unload-reload loops that virtually lie on top of one another, which is further evidence of elastic behaviour during these unloading and reloading cycles. The elastic modulus on the first loop is 66.8 $\mathrm{MPa}$; by the time the peak is reached the modulus has dropped to between 50.6 and $56.4 \mathrm{MPa}$; and by the time a "residual" or "steady state" condition is reached the modulus has dropped to less than half of the 
original value. This reduction in modulus with accumulating plastic strain is consistent with the notion of "damage" as used in continuum damage mechanics.

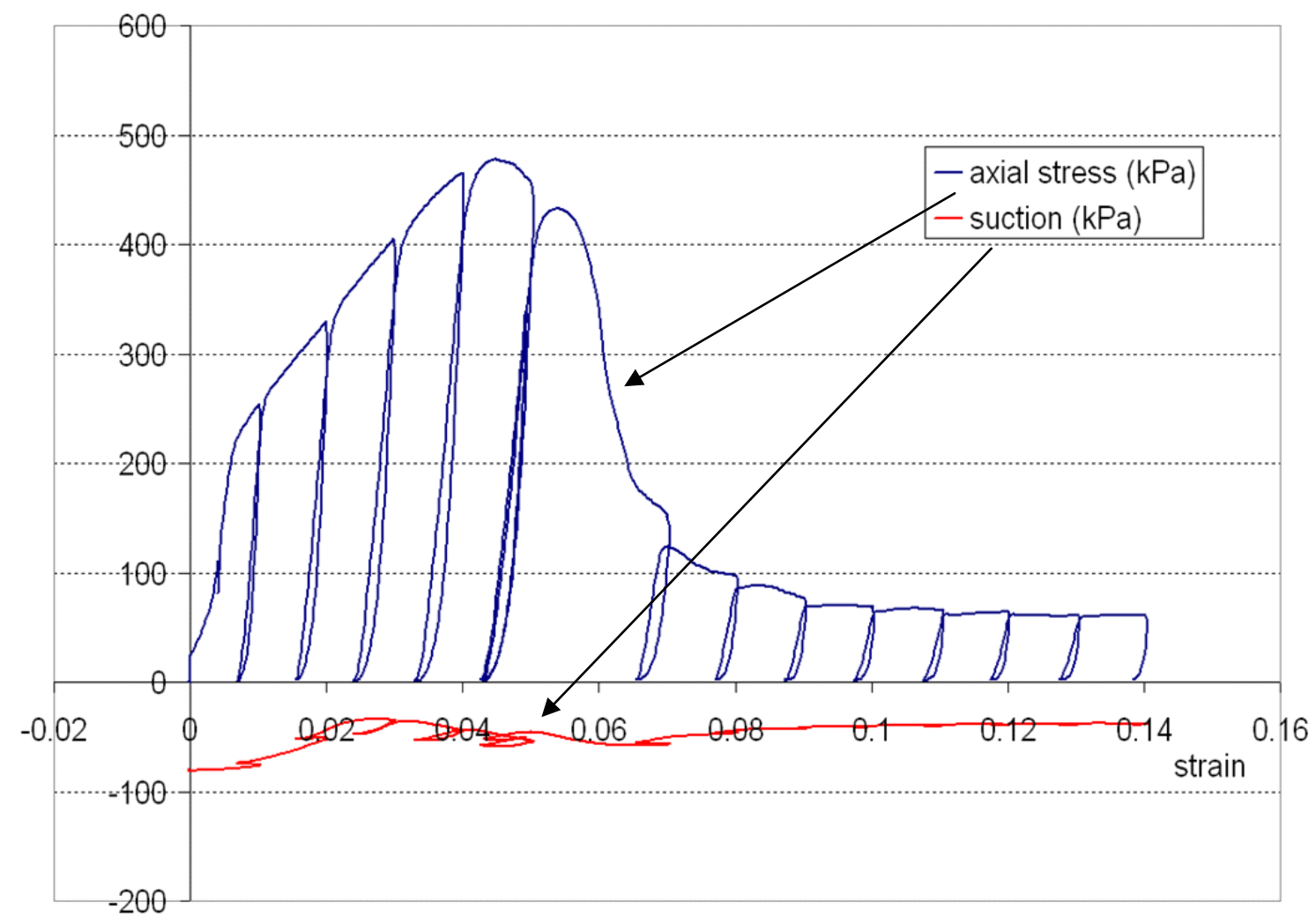

Figure 6 Static cyclic triaxial response of a CPB specimen with suction

Table 1 Elastic moduli and accumulated plastic axial strain for the unload-reload loops shown in Figure 6

\begin{tabular}{|l|l|l|}
\hline Cycle \# & Modulus (MPa) & Plastic axial strain \\
\hline 1 & 66.8 & 0.007 \\
\hline 2 & 59.1 & 0.016 \\
\hline 3 & 57.9 & 0.024 \\
\hline 4 & 56.4 & 0.033 \\
\hline $5 / 6$ & 50.6 & 0.043 \\
\hline 7 & 31.6 & 0.066 \\
\hline 8 & 25.8 & 0.077 \\
\hline 9 & 21.6 & 0.088 \\
\hline
\end{tabular}

Further examination of the unload-reload cycles in Figure 6, in particular the peak stresses obtained for each loop upon reloading which may be taken as indicative of the end of elastic behaviour and the onset of elastoplastic behaviour, reveals that the material is continuously yielding from early on in its loading history, and that the initial rise in the stress-strain envelope may be taken as indicative of strain hardening behaviour up to the peak stress, followed by post-peak strain softening behaviour. Another way of interpreting this elastoplastic phenomenon is to look at the stress paths for each unload-reload cycle in q-p' stress space, as is shown in Figure 7. 


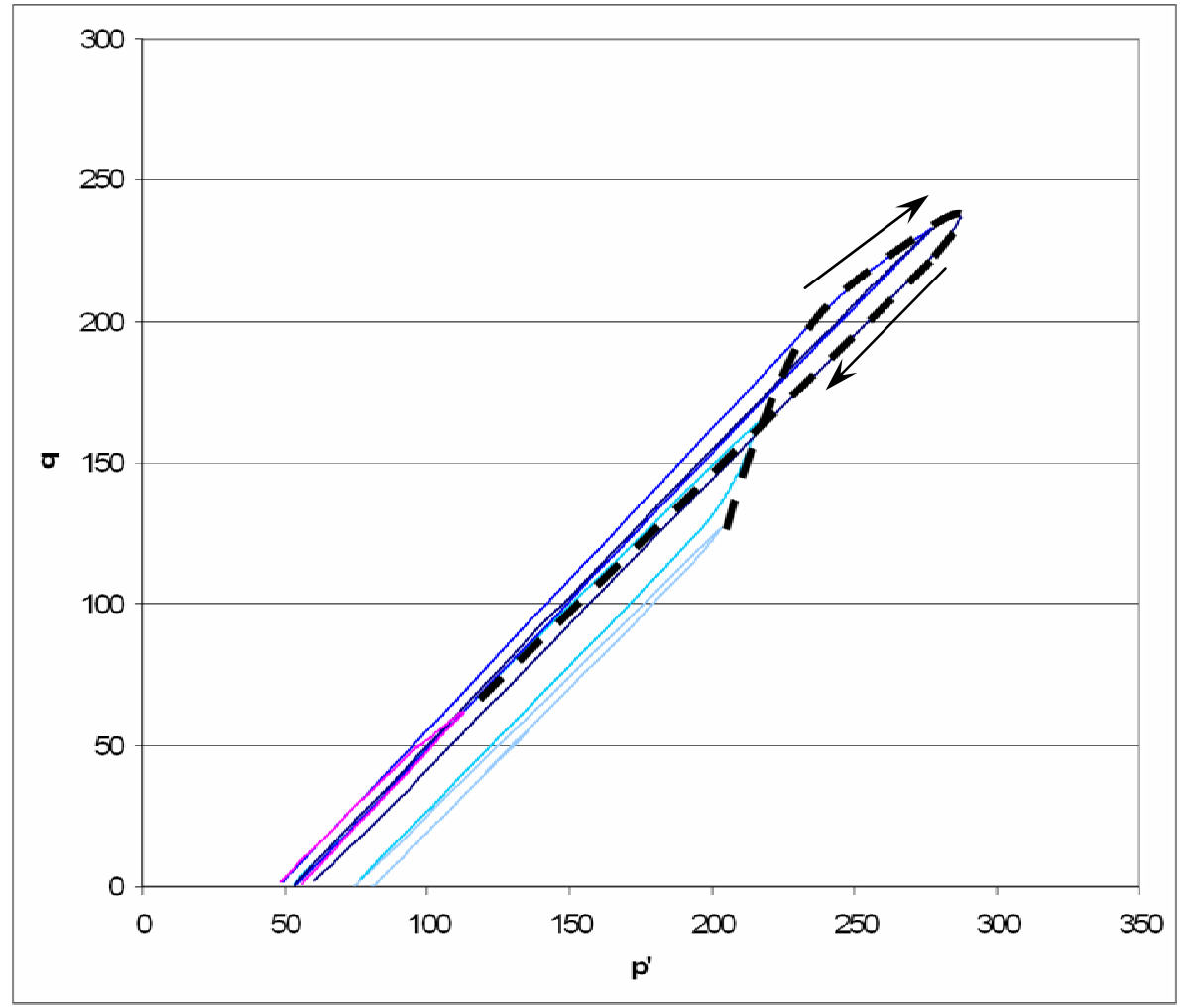

Figure $7 \quad$ Locus of q-p' stress points lying on the failure surface (dashed line) showing strain hardening (rising portion) and softening (falling portion)

The unload-reload loops in Figure 6 may be used to aid the interpretation of each loop in q-p' space and to identify the elastic components of the loops versus the strain hardening or strain softening components. These latter components are portions of the stress path that lie on the yield surface in stress space, although it must be recognized that for a strain-hardening/softening material the yield surface is actually moving with accumulating plastic strain. Therefore we can at best trace out a locus of points lying on the yield surface, as is done in Figure 7. Note that as this locus approaches the peak stress its trace appears to become asymptotic, and indeed it may be that the tangent to this portion of the locus describes a familiar c- $\phi$ ' strength envelope; however, further testing is required to better understand this phenomenon.

\section{CONCLUSIONS AND FUTURE WORK}

Mine backfilling scenarios exist in which the hydraulic and mechanical properties of the fill change at rates similar to the rate of fill rise. As a result, the in situ hydraulic and stress conditions can generally be quite complex and are at present poorly understood. This has important implications for many practical design issues. For example, the development of increased mobilized strength arising from the development of suctions will tend to enhance arching, especially in narrow stopes, which has the beneficial effect of reducing pressures on fill barricades. Barricade construction might therefore be simplified, reducing construction time and therefore possibly cycle time. The development of suctions, or at least reduced development of pore 
water pressures, would also permit faster stope filling without the risk of liquefaction under self-weight loading. If the suctions also act in the long term then this will reduce the time required until production blasting in proximity to the fill may be resumed without the risk of dynamically-induced liquefaction. A better fundamental understanding of CPB's transient properties is therefore required, including the coupling between hydraulic and stress properties which controls, for example, the observed self-desiccation phenomenon. The types of tests described in this paper and other similar tests continue to be used in an effort to develop the required fundamental understanding and subsequent mine design tools.

\section{ACKNOWLEDGEMENTS}

Primary funding for this research came from the Natural Sciences and Engineering Research Council Canada in the form of a Post-Doctoral Fellowship to the second author and a Discovery Grant to the first author. The 1-D unsaturated compression tests were carried out by Mr. Michael Diez d'Aux as part of his Undergraduate Bachelor's Thesis at the University of Toronto. The unsaturated triaxial testing was carried out during a summer work term by Mr. Yakob Woldeyesus, an undergraduate student in the Lassonde Mineral Engineering Program at the University of Toronto.

\section{REFERENCES}

Acker, P. (2004) Swelling, shrinkage and creep: a mechanical approach to cement hydration. Materials and Structures: Concrete Science and Engineering, 37 pp. 237-243.

Godbout, J., Bussière, B., Aubertin M., Balem, T. and Benzaazoua, M. (2004) Évolution des propriétés de rétention d'eau des remblais miniers cimentés en pâte durant le curage. Proceedings of the 57th Canadian Geotechnical Conference, Quebec City.

Grabinsky, M.W., Simms, P., Bawden, W.F. and le Roux, K. (2005) In situ properties of cemented paste backfill and implications for mine design. Symposium 2005 on Mines and the Environment, Rouyn-Noranda.

Kim, J.-K. and Lee, C.-S. (1999) Moisture diffusion of concrete considering self-desiccation at early ages. Cement and Concrete Research, 29 pp. 1921-1927.

le Roux, K., Grabinsky, M.W. and Bawden, W.F. (2002) Laboratory analysis of consolidation and hydration of cemented paste backfill. Proceedings of the 55th Canadian Geotechnical Conference, Niagara Falls.

le Roux, K., Bawden, W.F. and Grabinsky, M.W. (2004) Liquefaction analysis of early age cemented paste backfill. Eighth International Symposia on Mining with Backfill (Minefill 2004), Beijing.

le Roux, K., Grabinsky, M.W. and Bawden, W.F. (2005) Consolidation and fabric development in cemented paste backfill. Trans. Instn Min. Metall. (Sect. A:Min. Technol.), in publication. 